\title{
Article
}

\section{Risk Assessment of Moored and Passing Ships}

\author{
Peter Vidmar ${ }^{1, *}$, Marko Perkovič ${ }^{1}{ }^{(\mathbb{D}}$, Lucjan Gucma ${ }^{2}$ and Kinga Lazuga ${ }^{2}$ \\ 1 Faculty of Maritime Studies and Transport, University of Ljubljana, Pot pomorščakov 4, \\ 6320 Portorož, Slovenia; marko.perkovic@fpp.uni-lj.si \\ 2 Maritime University of Stettin, Wały Chrobrego 1-2, 70-500 Szczecin, Poljska; \\ l.gucma@am.szczecin.pl (L.G.); k.lazuga@am.szczecin.pl (K.Ł.) \\ * Correspondence: peter.vidmar@fpp.uni-lj.si
}

Received: 31 August 2020; Accepted: 25 September 2020; Published: 29 September 2020

\begin{abstract}
Accidents in port areas are generally relatively minor given the lower prevailing speeds, but dangerous cargo terminals located in the vicinity of populated areas present some risk of accidents with catastrophic consequences. The maritime risk assessment frameworks have been developed in many ports, but few include studies incorporating collisions between sailing and moored ships. This paper presents the risk assessment framework for such accidents. Moreover, it presents the important role of harbour regulations in the navigation risk management process within the port area. Today's port regulations are created mostly based on the good practice of pilots and other experts, whereas quantitative methods are used less frequently. The intention of the presented case study was to demonstrate how quantitative risk assessment may be used in port policy development, which is why the method created is general and may be used in any terminal with dangerous cargo. The multi-stage method consists of several steps that make up a complex methodology, consisting of expert study, real-time simulation-a simulation of a collision in port is presented-and analytical-empirical calculations for consequence assessment. The case studies of the developed method are presented based on two real accidents, one in the Police port along the Świnoujście-Szczecin waterway, and the second in the Port of Koper in Slovenia. The results of this study present the parameters of the ship's safe approach to the terminal area, such as velocity and approaching angle. These parameters are used to calculate the impact forces in the case of a collision between a moored and passing ship and its consequences on ship integrity as well as on mooring arrangement. Based on probability and consequences, the risk is evaluated and discussed in the sense of port safety. The presented method could be used as the framework for risk assessment of collisions in a port area, particularly when dealing with dangerous cargo or sensitive vessels such as cruise ships.
\end{abstract}

Keywords: port accidents; risk assessment; terminal safety; harbour regulations; mooring; collision energy

\section{Introduction}

Due to the nature of their business activity and complexity ports are highly challenging in regard to the development and implementation of a port safety management system (PSMS). Moreover, the interests of groups with opposing goals need to co-exist in ports. The Harbour Master plays a crucial role, being responsible for overall port safety, implementation of safety regulations and PSMS, information exchange, the environment, and security within the ports. Unfortunately, there is a lack of global regulation in this area [1]. There have been several attempts and case studies made to attempt to create such regulations [2], but there are serious obstructions, in particular because such a framework must satisfy global, regional, local, and industrial regulations. 
The global maritime community is subject to International Maritime Organization (IMO) regulation, where port should implement the International Ship and Port Facility Security Code (ISPS) as the general regulatory framework [3]. Detailed safety and security procedures are instead regulated by national rules of port regulations. The most comprehensive and elaborated legal framework for PSMS is the UK Port Marine Safety Code [1] which introduced a formal risk assessment including the As Low As Reasonably Practicable (ALARP) concept. A similar comprehensive concept has been implemented in New Zealand and is applied in other countries such as the U.S., Canada, and the Netherlands [4]. The risk management procedure applied according to this standard is based on the following steps: data gathering and familiarization, hazard identification, risk analysis, risk assessment, and risk control. Several attempts have been made to link IMO Formal Safety Assessment (FSA) [5] with PSMS, but serious limitations have been observed, such as the influence of different standards of operation, especially for dangerous cargo handling terminals; the influence of constantly changing port infrastructure; that serious maritime accidents in ports are rare events; the belief of decision makers that due to low energies and ship speed reduction in ports, the risk is lower than typically calculated; and that ship traffic influence and the significant influence of a human factor must be taken into account [6].

Port regulations (port bylaws) have a significant role in the safety management process as a major implementer of Risk Control Options (RCO). Additionally, several relevant documents exist in ports: terminal safety procedures, terminal operational procedures and procedures of accidents consequences mitigation (such as contingency planning). Port regulations are often created based on expert opinions (pilots, Harbour Master) using specific local knowledge. The dangerous cargo terminals (oil, gas or chemical) usually operate under an international industrial legal framework created by organizations such as Oil Companies International Marine Forum (OCIMF) or International Chamber of Shipping (ICF).

This paper first presents the need of a port to assess the risk between the approaching and a moored ship. The risk is defined as a potential loss of property and the risk criteria are related to the revenue of the analysed port and the cost of an average accident. According to the risk calculation the probability of accidents is calculated for two different ports according to the specifics of the approaching channels and piloting procedures. Next, the consequences are analysed with the energy collision model supported by the kinematic model of mooring ropes. The result is the evaluation of the limit velocity of the ship approaching the terminal to keep consequences of a collision within a reasonable limit. The last is the evaluation of the risk applying the event tree approach considering the likelihood of the collision events and their consequences estimated in costs. The risk is presented with the F-N function comparing the two analysed ports.

Again, accidents in port areas are rare events, especially those with significant consequences. This may be problematic in creating proper methodologies of their analyses and could lead to poor policy decisions [5-7]. The risk assessment in port areas is a process wherein all possible hazards should be taken into account [8,9]. Several complex methodologies of risk assessment have indeed been developed $[10,11]$ but there is no detailed solution for risk assessment in regard to mooring ships with dangerous cargo, except for problems related to excessive waves generated by passing ships [12]. The studies made by [13] showed that port infrastructure facilities significantly affect vessel exposure to risk. In addition, studies made by [14] and an earlier one, made by [15], stressed this problem and revealed that FSA methodology might be insufficient given constantly changing port infrastructure. Moreover, the authors demonstrate in this paper that the problem has a complicated spatiotemporal nature due to variability in quay occupation, which makes the situation even more complex.

In the presented study, the so-called potentially catastrophic scenario (PCS) is introduced to find the risk of a ship colliding with a moored ship due to technical failure. The PCS is developed here by the combination of several analytical methods involving simulation of the impact energy. There is a potential possibility of a scenario with even higher negative outcomes, but the probability of such 
accidents in port has been assessed as extremely low, because of low approaching speeds, and it is not taken into consideration.

Two accidents are described in this paper, neither of which caused significant consequences, but are used to demonstrate the ability of the proposed methodology to evaluate the risk of in-port manoeuvring operations. The first is a collision between the ship Altamar and the bunker ship Palica, moored side by side, into the 250 passengers Ro-Pax ferry Baltivia in Świnoujscie Ferry Terminal, Poland. The second is the collision between the container ship UASC MADINAH and the cruise ship Thomson Spirit Valletta in the port of Koper, Slovenia, Figure 1. Even though these accidents occurred between different types of ships and in different ports, the risk evaluation approach may be the same and the implementation of the RCOs transferred from one country or port to another.
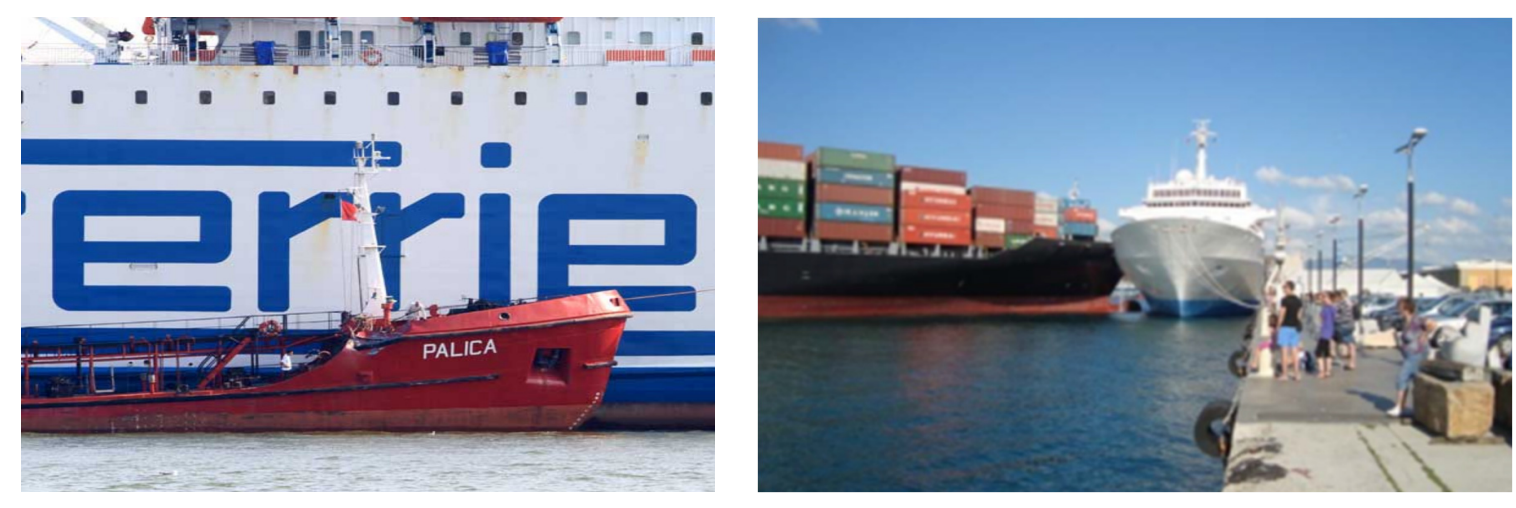

Figure 1. View of two collision events in a port area, Świnoujscie terminal (left) and Port of Koper (right).

Luckily, neither leakage of bunker liquids nor fire resulted from these accidents. The damage to the Palica tanker was around half of a square meter located on the forecastle a safe distance from the bunker ship tanks. The case of the container ship colliding with the cruiser caused more damage to the hull, but the load line area was not damaged.

\section{Risk Assessment Framework}

Several methods of maritime risk analysis dedicated mostly to coastal and open sea areas have been developed [16-19]. The general risk assessment framework of dangerous cargo terminals located in the vicinity of waterways in respect to possible collision is presented in Figure 2. The overall framework of formal risk assessment for shipping in coastal and open seawaters is presented by [20]. However, in the port area, several differences are observed. Firstly, in port areas, impacts are both generally minor and more likely. Secondly, there are human populations in the port areas that may be threatened by toxic substances released during a collision. The navigation process is also different-usually there are several persons on the bridge performing overlapping tasks (pilot, captain, OOW-officer on watch). The Vanem framework classifies the collision with a moored ship accident as one which could lead to misunderstandings, especially when analysing the causes of accidents. The proposed multi-stage procedure requires applying the following five sub methods:

1. Expert's method for identification scenario of toxic substance release,

2. Real- or fast-time simulation modelling to find the geometry of collision and highest possible speed of the moving ship,

3. Mathematical models of external and internal ship dynamics,

4. Model of pollution dispersion,

5. Model of consequence to humans, including passengers with consideration of exposure to the chemicals. 


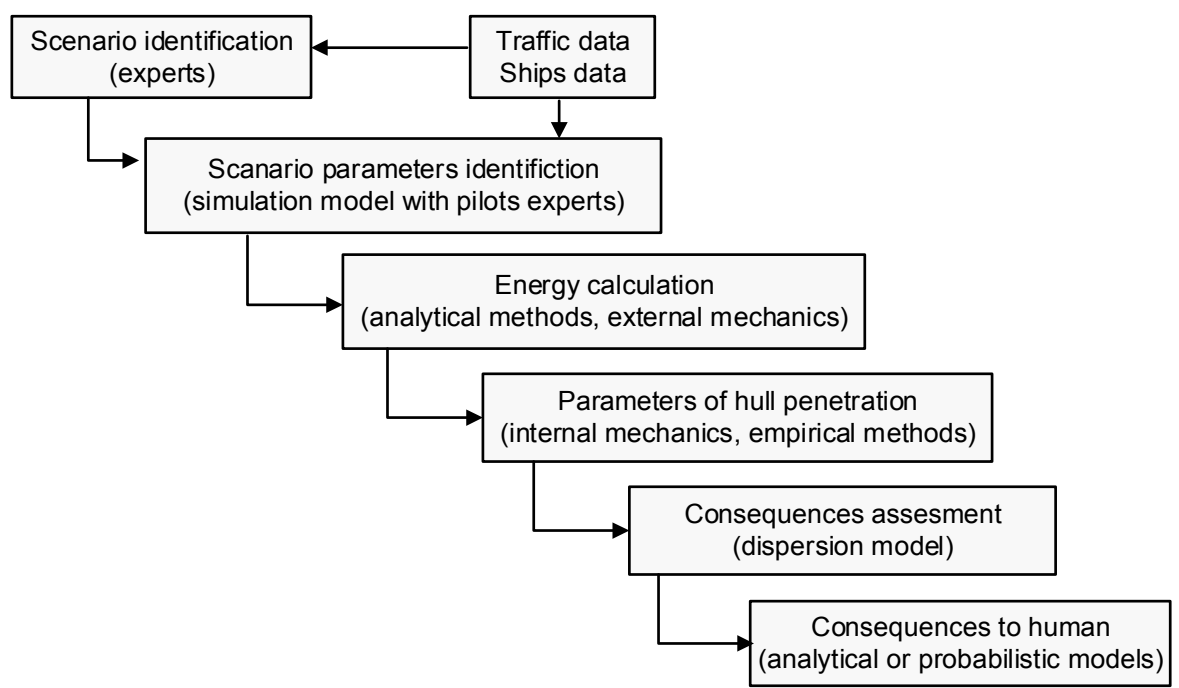

Figure 2. Risk assessment framework for moving ship colliding with moored tanker applied in this study.

The consequence of the concept applied in this study is related to the accident energy released and with the depth of the moored ship hull penetration. In the presented cases, there is a safety barrier: the ballast tank located on the ship's side denoted by $d_{b}$. For the purpose of this study, when the potentially catastrophic scenario is taken into account, the risk is calculated as a product of probability and consequences only when the depth of penetration could reach a tank with fuel.

Acceptable risk is not specified in Polish or Slovenian legislation for such maritime systems [8,21]. Moreover, there is not enough operation time of such vessels in the studied area to develop acceptable risk standards based on statistical data as described by Kristiansen [11]. The risk acceptance criteria are therefore calculated based on the potential loss of property [22]. The risk of losing part or all of the port revenue and costs of ship damage or total loss is an economic risk that primarily influences the company policy. The world fleet statistics show that the number of accidents is increasing with the increase in the number of ships sailing. On the other hand, the consequences of accidents are less severe thanks to the continuous maritime standards improvements for ship construction, electronic navigation control, shore vessel traffic services, and more.

The risk of property loss is here calculated as:

$$
P L P_{A}=r_{p} \times E V
$$

where $E V$ is the average revenue of the port per ship year and $r_{P}$ is the loss of property for accidents per average port revenue per year.

$$
r_{P}=\left(C_{a_{-} c} / r e v_{a_{-} y}\right),
$$

where $C_{a_{-} c}$ is the average collision cost per ship year and $r e v_{a_{-} y}$ the average revenue of the port per year.

The unit for $P L P_{A}$ is the ratio of property loss in M EUR/ship year M EUR business economic value. Further, the frequency of property loss is calculated with Equation (3), where $N_{u}$ is the cost of a total loss depending on ship type. An average value of $\sum_{N=1}^{N u} \frac{1}{N}$ for Panamax size is 4.5 , where $N$ is 1 to the maximum property loss in M EUR [23].

$$
F=\frac{P L P_{A}}{\sum_{N=1}^{N u} \frac{1}{N}},
$$


For the year 2018, the tolerable damage cost $F$ is calculated as $1.34 \times 10^{-3}$ property lost M EUR/ship year. The acceptable area around this value is defined by factor 0.1 and 10, respectively, for the low and high sides [9].

\section{Determination of Accident Scenarios and Probability}

One of the most appropriate approaches to assessing the safety of complex marine traffic engineering systems is the use of stochastic simulation models [8]. The model could be used for almost all navigational accident assessments, such as collisions, groundings, contact with fixed objects, indirect accidents such as anchor accidents or accidents caused by ship-generated waves. The model could comprise several modules responsible for different navigational accidents.

The design of the collision model was divided into 4 stages. The main goal of this model is to calculate the probability of collision for a given type of encounter. Because there are no statistical data about collisions in the Gulf of Trieste and Koper, the probability calculated for the Baltic Sea was used.

Stage I-Division of the encounters into characteristic types

1. Head-on encounter-difference of headings $170^{\circ}-190^{\circ}$ and distance less than critical

2. Overtaking - difference of headings more than $350^{\circ}$ or less than $10^{\circ}$ and distance less than critical

3. Crossing-difference of headings (rest of cases) and distance less than critical

The critical distances where navigators perform anti-collision manoeuvres was assumed on the basis of expert opinions separately for each type of situation.

Stage II-Calculation of the number of encounters of each type

For the southern part of the Baltic Sea, the overall number of encounters estimated by the simulation model is around 140,000 per year where $30 \%$ of them are head-on situations, $40 \%$ crossing and $30 \%$ overtaking. It could be done for the Gulf of Trieste, but due to lack of collision data it would be pointless.

Stage III-Study of the statistical data and evaluation of the intensity of collisions

For the southern part of the Baltic Sea the mean intensity of collision accidents equals 2.2 per year. Only the accidents on the open sea area were considered.

Stage IV-Calculation of the probability of collision for a given type of situation

To simplify the calculations, it was assumed that the intensity of collision was equal in all considered situations. Data for collision probability simulation were obtained from AIS data collection at each port.

1. Head-on encounter- 0.73 collisions per year

2. Overtaking- 0.73 collisions per year

3. Crossing- 0.73 collisions per year

The probability of collision for a given type of encounter can be calculated by using the following formula:

$$
P_{c}=\frac{I}{n_{E S}},
$$

where $P_{C}$ is the probability of collision for a given type of encounter, $I$ is the intensity of collision for a given type of encounter and $n_{E S}$ is the number of encounters of a given type. The Poisson distribution is popular for modelling the number of times an event occurs in an interval of time or space and was here used to model the number of ships on each route $[17,22]$ : 


$$
f(k, \lambda)=\frac{\lambda^{k} e^{-\lambda}}{k !}
$$

where $k$ is the number of ships occurring on a given route in one step of simulation and $\lambda$ is the expected number of ships that occur during the one step of simulation.

Coordinates of way points were modelled using two-dimensional normal distribution. The normal distribution of ship routes in a navigation channel was found from the analysis of ships AIS data for both ports and can easily be modelled. Each coordinate of each way point for a ship on a given route was generated separately with the use of the following formula:

$$
f(x)=\frac{1}{\sigma \sqrt{2 \pi}} e^{-\frac{(x-\mu)^{2}}{2 \sigma^{2}}},
$$

where $\mu$ is the mean coordinate (latitude, longitude) of a way point and $\sigma$ is the standard deviation.

Several kinds of technical accidents with the highest expected consequences were analysed. The following accidents were taken into account:

1. Passing ship is losing its propulsion but rudder is working (not considered in this study because the ship is controllable, so this accident type is also rare),

2. Passing ship's rudder is blocked but propulsion is operable, Polish case, (selected in this study since the propeller still produced water inflow to the rudder causing a turning effect),

3. Passing ship losing its propulsion and rudder is blocked due to extensive "black out", Slovenian case (similar to above but the ship is decelerating).

The following are the results for the traffic analysed for the complete area presented by Figure 3 or the traffic lane calling at the Świnoujście and the Port of Koper traffic waterways.

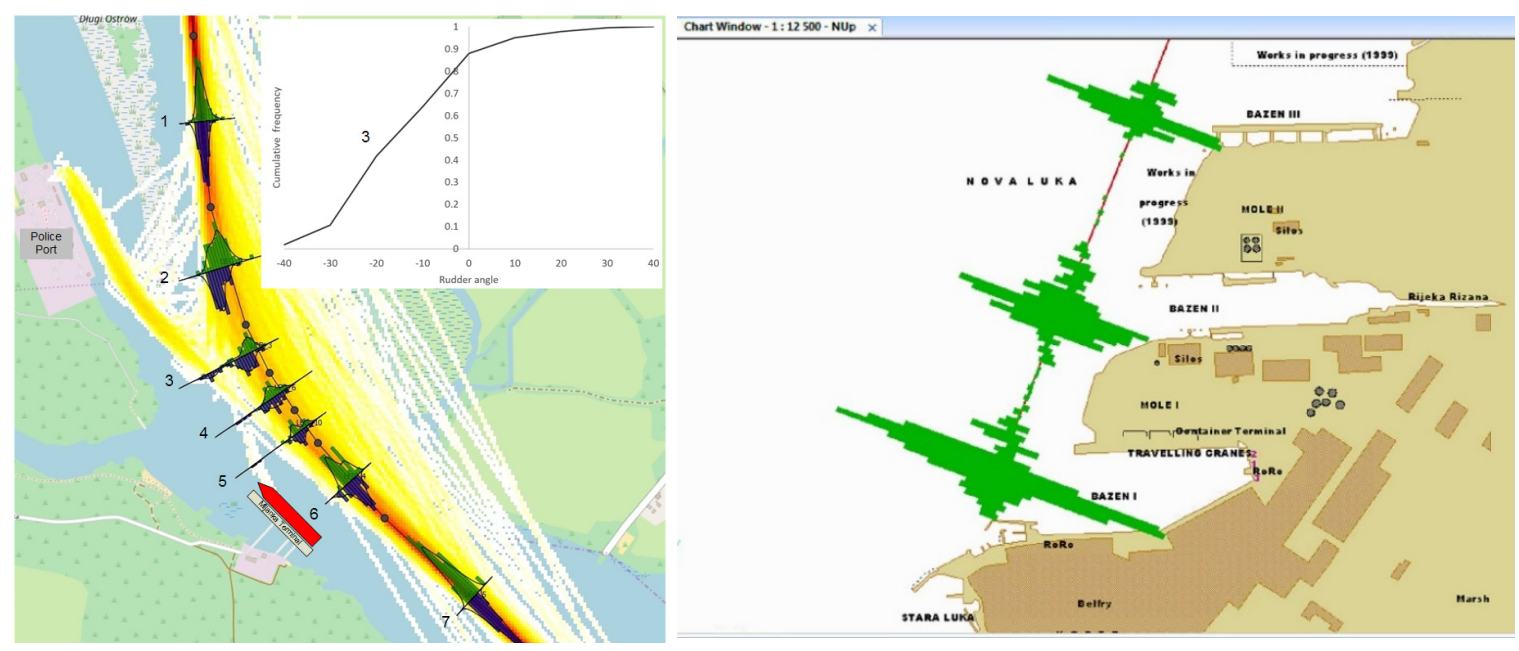

Figure 3. Distribution of ships traffic of length more than $150 \mathrm{~m}$ (AIS data) for the Świnoujście waterway-(left) and the entrance to Koper bay-(right) and in insert the cumulative distribution of rudder angle in Section 3 as a result of real time simulation study. 
To find the candidates for collision, the ship traffic passing through the Świnoujście-Szczecin waterways in the vicinity of the terminal was analysed. The middle of the waterway was divided into several sections. The traffic distributions (histograms in gates No 1 to 7 ) from 2 years of AIS data observation (2015-2016) are presented in Figure 3. To find the PCS accident and maximum possible values of speed and impact angle due to manoeuvring characteristics of ships for the determination of further consequences, the real time simulation model described by [24] was applied, and the accident situation was simulated several times to find the worst possible values for use as parameters of consequences. In each waterway section presented in Figure 4, the real time accident simulations were performed to find the maximum angle and speed of the colliding vessel. The entire procedure was as follows:

1. Place the ship model in starting position in three selected Sections 2-4 (in 5 different points for given section with highest probability, so 15 simulation runs were made),

2. Start the simulation,

3. Set the rudder angle to the maximum assumed for this type of ship,

4. Set engine to stop,

5. Observe and record following data: if the moored ship was struck, angle of contact, speed of contact.
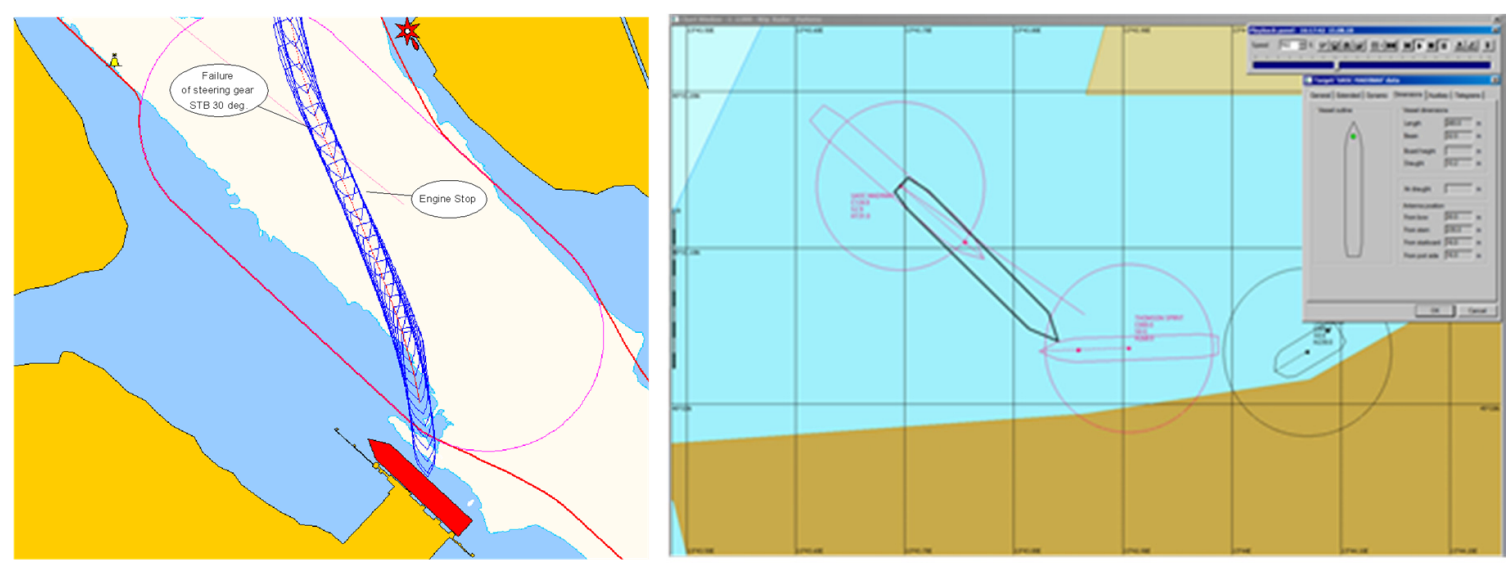

Figure 4. Simulation model result of cruise vessel striking the moored chemical tanker at the angle of $44^{\circ}$ and speed $2 \mathrm{~m} / \mathrm{s}$, after its technical failure in Poland (left) and the collision of the container ship into the passenger ship in Koper (right).

The above procedure could be considered as manual optimization, where the goal was to achieve the maximum angle of collision and speed during the collision. The most critical parameters for the consequences of the accident were found, and they were the angle of collision $44^{\circ}$, speed $4 \mathrm{~m} / \mathrm{s}$ (with engine stopped) and $2 \mathrm{~m} / \mathrm{s}$ (with engine reversed). In the Slovenian case, the colliding ship had a speed of $2.9 \mathrm{Nm} / \mathrm{h}$ and angle of collision $56^{\circ}$.

The probability of collision in Equation (7) is further calculated where the most important factor is the hourly probability of rudder failure $\left(P_{t}\right)$, which stands for rudder system failure.

$$
P=I_{w} I_{t} t_{w} t_{t} P_{t} P_{r}
$$

where $I_{w}$ is the intensity of waterway traffic; $I_{t}$ is the intensity of ships in terminal; $t_{t}$ is the terminal occupation time $t_{w}$ is the time of passing near moored ship; $P_{t}$ is the probability of technical failure; and $P_{r}$ is the probability of rudder angle position. 
This value was determined by [8] using a database of more than 77 ships of the Polish owner Polsteam over 7 years of operation. The expected value during ship passage is $4.8 \times 10^{-4}$ per hour of ships operation. For realistic traffic and input data for the police port: $I_{w}=300$ ship/year, $I_{t}=40 \mathrm{ships} /$ year, $t_{t}=24 \mathrm{~h}, t_{w}=0.5 \mathrm{~min}$, and $P_{r}=0.05$ (starboard $30 \mathrm{deg}$.), we obtain the probability of collision due to technical failure of the rudder estimated as $8.9 \times 10^{-6}$ yearly.

For the Port of Koper, the expected frequency of collision is calculated from Equation (1), according to the simulated traffic flow from Equation (2) and Equation (3). The result is $8.3 \times 10^{-4}$ per ship year with large spill consequence for 800 ships/year. The frequency of contact with lesser consequences is evaluated for 15 years of statistics and is $1.8 \times 10^{-3}$ per ship year.

\section{Determining the Consequences of an Accidents}

Several methods for assessing ship damage resultant from collision have been developed. The comprehensive study of today's methodology of ship collision consequences is presented in [25] and [26]. These methods in terms of the number of input parameters can be divided into dedicated methods (numerical methods), general methods requiring only general parameters (analytical), and combined methods $[27,28]$. The method presented in this paper belongs to the second class and includes some simplifications so that it can be applied easily with only general assumptions about the parameters of the ships involved in the collision. The procedure for determining the consequences of collisions comprises the following steps:

1. Determine the collision scenario,

2. Determine the energy released during the collision considering rigid body dynamics,

3. Identify the material damaged in a collision,

4. Determine the expected maximum distance of penetration of the hull,

5. Determine whether the acceptable risk was exceeded - i.e., that the cargo tank may have been damaged.

\subsection{Energy Released during Collision (External Dynamics)}

The energy is determined separately from the standpoint of movement before and after the collision assuming that the movement of the ship can be described by the following equations of motion:

$$
\begin{gathered}
m\left(1+m_{x}\right) a_{v x}=-F_{\varsigma} \sin \alpha-F_{\eta} \cos \alpha \\
m\left(1+m_{y}\right) a_{v y}=-F_{\varsigma} \sin \alpha-F_{\eta} \cos \alpha \\
m R^{2}(1+j)=-F_{\varsigma}\left[y_{c} \sin \alpha-\left(x_{c}-x_{a}\right) \cos \alpha\right]-F_{\eta}\left[y_{c} \cos +\left(x_{c}-x_{a}\right) \sin \alpha\right]
\end{gathered}
$$

where $m_{x}, m_{y}, j$ are coefficients of added water in surge sway and yaw motions; $a_{v x}, a_{v y}$ are accelerations of the striking ship in the $x$ and $y$ axis; $R$ is the radius of ship's inertia; $F_{\zeta}, F_{\eta}$ are forces in $\zeta$ and $\eta$ directions during collision; $a$ is the angle of contact; $x_{a}$ is the ship's centre and $x_{c}, y_{c}$ is the point of contact.

The situation and coordinate system are presented in Figure 5. A further step according to the formulas of [29]: the energy is calculated considering two cases, with sliding of the colliding vessel alongside the moored ship and with no sliding. The coefficient of friction $\left(\mu_{0}\right)$ and restitution coefficient (e) are part of the model. The energy loss is expressed as in [30]:

$$
\begin{aligned}
& E_{\varsigma}=\int_{0}^{\varsigma m a x} F_{\varsigma} d \varsigma \\
& E_{\eta}=\int_{0}^{\eta \max } F_{\eta} d \eta
\end{aligned}
$$

where: $E_{\varsigma}$ and $E_{\eta}$ are energy lost in $\varsigma$ and $\eta$ direction. 


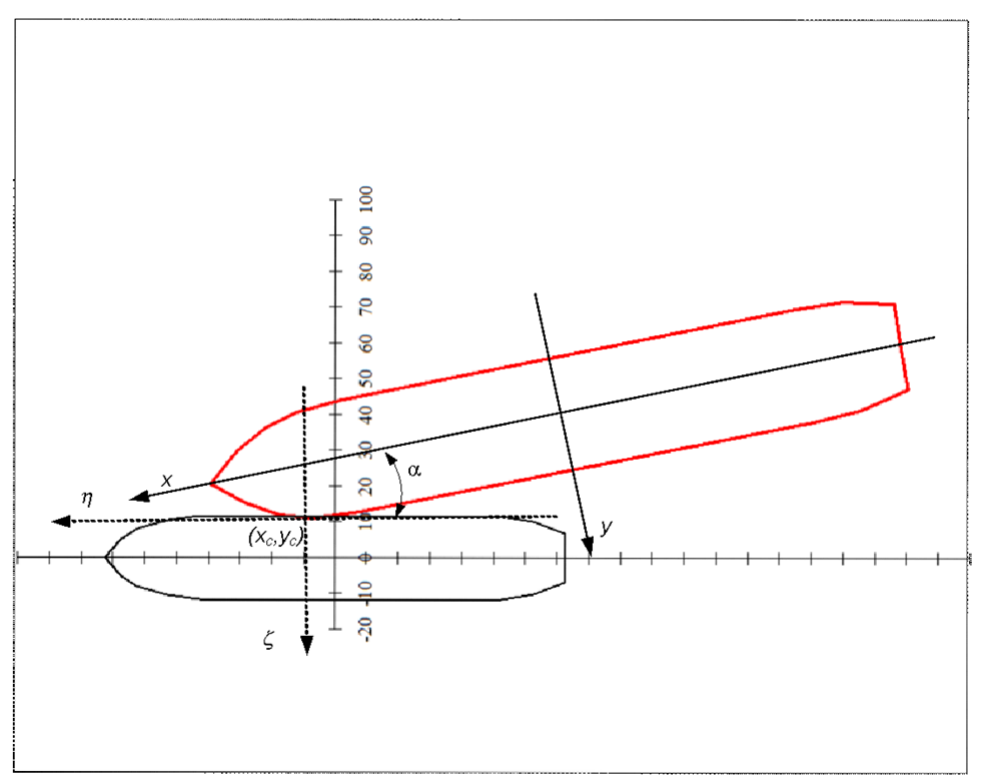

Figure 5. The $x y$ and $\zeta \eta$ coordinate system (collision with $\alpha=10$ deg. angle).

The detailed formulas in both cases are presented in [19]. Additionally, the total energy of the striking vessel $\left(E_{0}\right)$ is calculated as:

$$
E_{0}=0.5 m_{u x} v^{2}
$$

\subsection{Volume of Destroyed Material (Internal Dynamics)}

To determine the volume of material destroyed in a collision, two methods were used complementarily. For collisions of high-energy (>50 MJ), the modified Minorsky method was used, which was presented by [31] as the correlation presented in Figure 6 in the form of:

$$
E=47.087 R_{T}+28.4
$$

where $E$ is total energy absorbed in collision $(\mathrm{MJ})$ and $R_{T}$ is the damaged hull material $\left(\mathrm{m}^{3}\right)$.

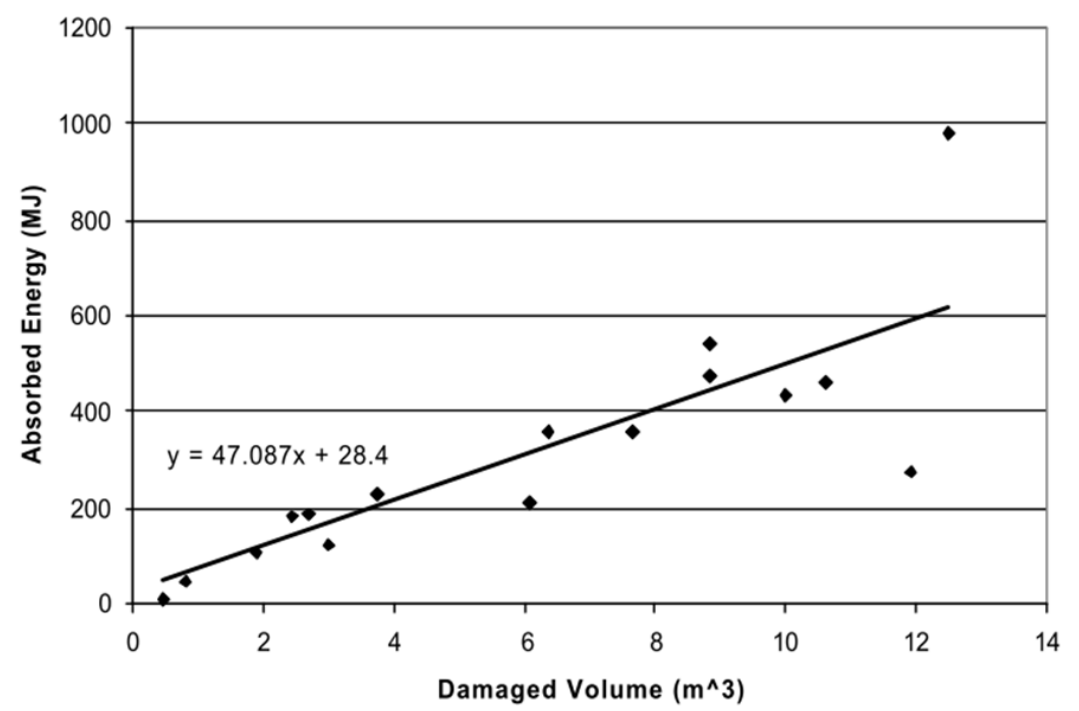

Figure 6. Reardon-Sprung method for determining the material damaged in ship-ship collisions [20]. 
In the case of low energy $(\mathrm{E}<50 \mathrm{MJ})$, the general method of [29] was used:

$$
E=3.5\left(\frac{t}{d}\right)^{0.67} \sigma R_{T}
$$

where $t$ is the plating thickness in the area of collision, and $d$ is the average size of plates, stiffeners and $\sigma$ is steel ductility limit $\left(\mathrm{N} / \mathrm{mm}^{2}\right)$.

\subsection{Assumptions for Tanker Damage}

Cargo ships in general are constructed with a similar integral tank configuration. The most threatening are the double bottom tanks used for engine fuel storage. During an angular collision, one of these could be penetrated and cause a severe oil spill and if the ship is a tanker, the penetration could reach a cargo storage tank. Several LPG tankers of similar size were used to calculate the average values of their parameters concerning the analysed tanker, as shown in Table 1.

Table 1. The parameters of studied tanker in terms of collision analysis needed for consequences estimation.

\begin{tabular}{cccc}
\hline Symbol & Value & Unit & Description \\
\hline$d_{b}$ & 1.6 & {$[\mathrm{~m}]$} & distance between tank and hull \\
$d_{d}$ & 2.5 & {$[\mathrm{~m}]$} & distance between tank and bottom \\
$d_{d z}$ & 27.5 & {$[\mathrm{~m}]$} & distance between tank and bow \\
$t$ & 35 & {$[\mathrm{~mm}]$} & plating thickness \\
$d$ & 2 & {$[\mathrm{~m}]$} & the average size of plates (stiffeners) \\
$t / d$ & 0.018 & {$[32]$} & ratio of $t / d$ \\
$\sigma$ & 270 & {$\left[\mathrm{~N} / \mathrm{mm}^{2}\right]$} & steel ductility limit \\
\hline
\end{tabular}

The key parameters for risk analysis-i.e., the distance of tanks from the sides, bottom and the bow-are shown schematically in Figure 7. Exceeding any of those parameters during the risk analysis results in unacceptable risk in this particular scenario.
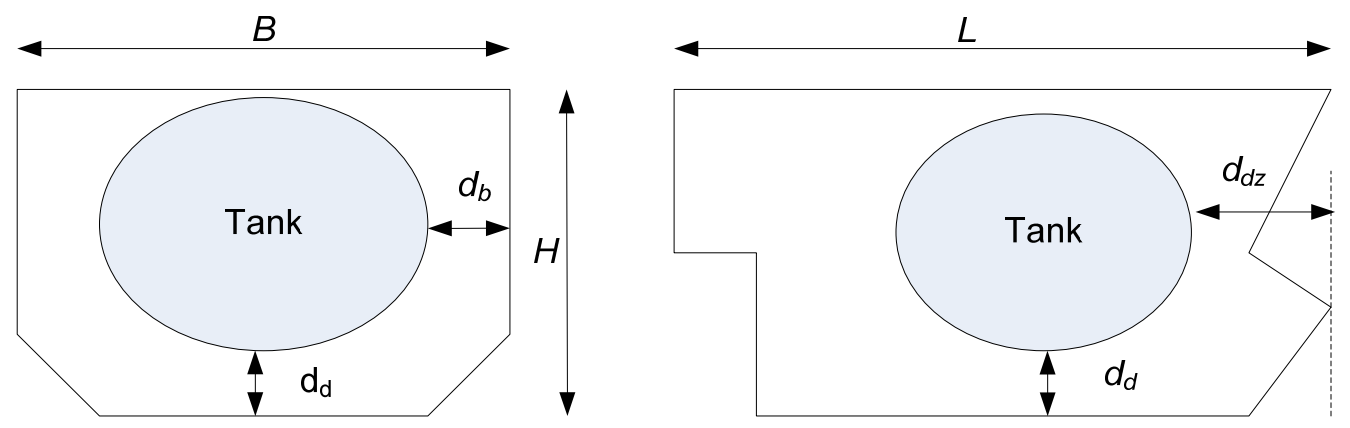

Figure 7. The critical distances for the tanks of chemical carrier.

\subsection{The Effects of a Collision with Another Ship on a Crossing Course}

It is assumed that the vessel does not move and is hit by the bow perpendicularly, which can cause the most severe effects. If the ship moves, the absorbed energy is lower given the losses of speed and slipping of the vessel after the accident.

As stated in the introduction, the first scenario assumes a simulated collision of a cruise ship with a length of $220 \mathrm{~m}$ approaching the Szczecin Port and a LPG tanker moored at its pier. The second is a real accident that occurred in the Port of Koper when a $265 \mathrm{~m}$ container ship collided with a cruise ship of $214 \mathrm{~m}$ length. Two collision scenarios were analysed in the study but only the consequences of the Slovenian case are presented below. The expected parameters of striking and struck vessels are presented in Table 2. 
Table 2. Parameters of vessels in study.

\begin{tabular}{cccccc}
\hline \multicolumn{2}{c}{ Poland Case } & \multicolumn{2}{c}{ Slovenia Case } & \\
\cline { 1 - 5 } Vessel & Striking & Struck & Striking & Struck & \\
\cline { 1 - 4 } Type & Cruise vessel & Ammonia tanker & Container vessel & Cruise vessel & \\
\hline$L[m]$ & 220 & 145 & 265 & 214 & Length \\
$B[m]$ & 31 & 23 & 32 & 27 & Breadth \\
$T[m]$ & 7.5 & 9 & 10.2 & 7.8 & Depth \\
$m[t]$ & 33,000 & 21,000 & 60,000 & 34,000 & Weight \\
$H[m]$ & 24 & 13 & 19.3 & 24 & Height to upper deck \\
$R_{h}[m]$ & 1.12 & - & 1.5 & 1.12 & ref. to Figure 8 \\
$R_{v}[m]$ & 3 & - & 3.5 & 3 & \\
$R_{l}[m]$ & 1.5 & - & 2 & 1.5 & \\
\hline
\end{tabular}
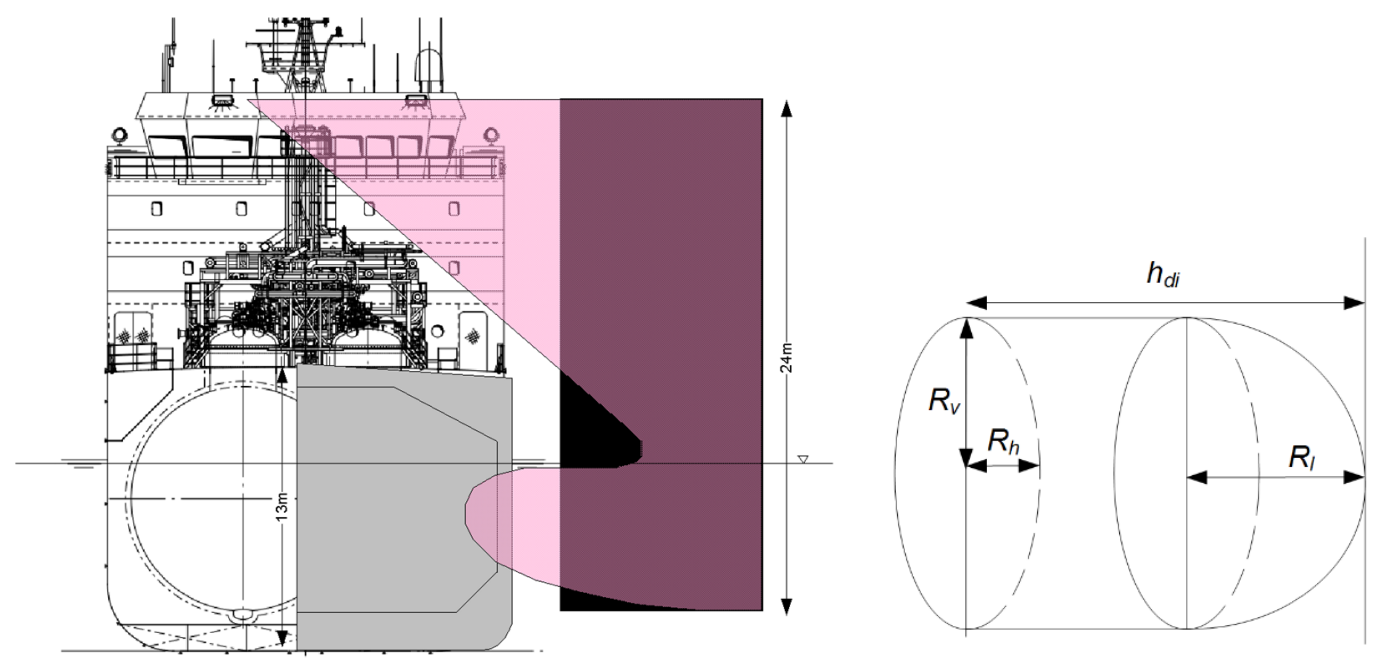

Figure 8. Side view of collision scenario and a simplified form of striking bulbous bow.

The shape of the bow part is assumed in simplified form as presented in Figure 8. The volume of the penetrating part could be expressed as a surface integral or calculated numerically as presented here according to a simplified bulbous bow expression as follows [29]:

$$
R_{t}=\sum R_{t}\left(h_{d i}\right)=\pi \sum \Delta h_{d i} \Delta R_{v i} \Delta R_{h i}
$$

where: $R_{t}$ is the volume of damaged material, $R_{v}$ is ellipse major axis and $R_{h}$ is ellipse minor axis. Applying the parameters of the stuck cruise ship in Equation (13) over different depth of penetration results in the penetration volume presented in Figure 9.

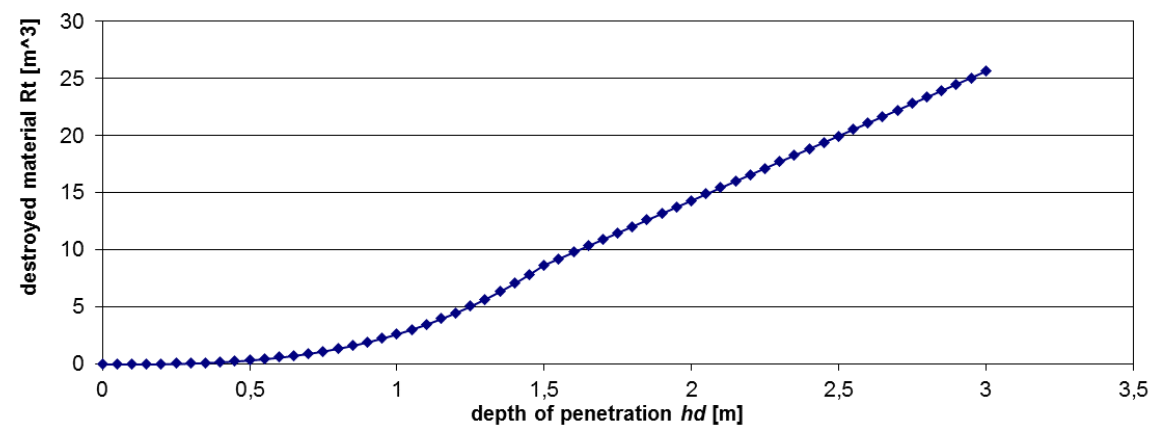

Figure 9. Numerical solution of depth of penetration by bulbous bow as function of destroyed material. 
In the literature, one can find information [29] as to how much energy is absorbed by the part of the bow of the colliding ship (due to the stiffness and construction of the bow part the values are given from 0 to $20 \%$ ). In the presented calculations, it was set as $0 \%$ as a conservative value, which means the bow of the colliding vessel is not damaged at all. The results of calculations are presented in Table 3. The energy, damaged material, and depth of penetration $h_{d}$ are shown. The colours indicating the exceeding of critical limit and the possibility of damage to the tank are marked according to the following ranges of $h_{d}$ :

1. Red-exceeded the value of $h_{d}$, certain damage to the tank i.e., $h_{d}>=1.5 \mathrm{~m}$,

2. Orange-likely damage to the tank, dangerous values: i.e., $1 \mathrm{~m}<h_{d}<1.5 \mathrm{~m}$,

3. Yellow-possible damage to the tank, values close to dangerous ones: i.e., $0.5 \mathrm{~m}<h_{d}<1.0 \mathrm{~m}$,

4. Green-minor damage $h_{d}<0.5 \mathrm{~m}$.

Table 3. Energy released, damaged material and the depth of penetration $h_{d}$ for chemical ammonia tanker struck in the side by a cruise ship with different parameters and speed.

\begin{tabular}{ccccccccc}
\hline & \multicolumn{4}{c}{ Energy [M] } & \multicolumn{4}{c}{ Depth of Penetration [m] } \\
\hline Speed/Angle & $\mathbf{1}$ & $\mathbf{2}$ & $\mathbf{3}$ & $\mathbf{4}$ & $\mathbf{1}$ & $\mathbf{2}$ & $\mathbf{3}$ & $\mathbf{4}$ \\
\hline 10 & 6.89 & 32.72 & 62.04 & 110.29 & 0.35 & 0.6 & 0.75 & 0.9 \\
20 & 13.57 & 62.31 & 122.17 & 217.20 & 0.45 & 0.75 & 0.95 & 1.15 \\
30 & 19.67 & 87.15 & 177.02 & 314.70 & 0.5 & 0.85 & 1.1 & 1.3 \\
40 & 24.87 & 106.57 & 223.82 & 397.90 & 0.55 & 0.9 & 1.2 & 1.45 \\
50 & 28.86 & 120.08 & 259.72 & 461.72 & 0.55 & 0.95 & 1.25 & 1.5 \\
60 & 31.26 & 127.28 & 281.38 & 500.23 & 0.6 & 0.95 & 1.25 & 1.6 \\
70 & 31.78 & 128.27 & 286.00 & 508.45 & 0.6 & 0.95 & 1.3 & 1.6 \\
80 & 31.78 & 128.27 & 286.00 & 508.45 & 0.6 & 0.95 & 1.3 & 1.6 \\
\hline
\end{tabular}

The energies released during the collision for the relatively slow surge speed of a cruise ship of $2 \mathrm{~m} / \mathrm{s}$ is presented in Figure 10. It can be observed that when the collision angle is higher than $60^{\circ}$, there is no sliding of ships. It could be found that almost $90 \%$ of initial energy is released when the angle is higher than $40^{\circ}$.

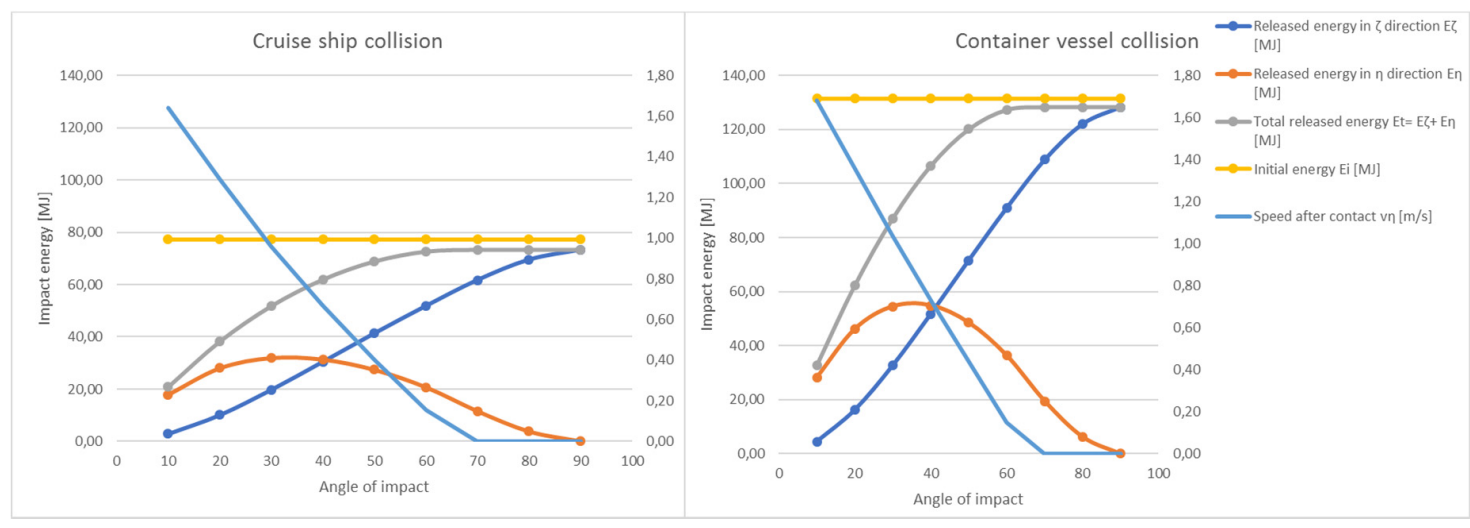

Figure 10. Energy release in $\zeta$ and $\eta$ directions for initial surge speed $v_{x}=2 \mathrm{~m} / \mathrm{s}$ (Cruise ship and Container vessel).

Table 3 indicates that a ship at $4 \mathrm{~m} / \mathrm{s}$ speed could penetrate the tanks of a moored ship with a 70 degree angle between the colliding ships. The maximum angle that is physically possible due to traffic distribution and hydrodynamic characteristics of colliding ships is estimated at about 50 degrees.

\section{Consequences of Collision on a Moored Ship}

The force exerted on a ship during a collision not only causes damage to the hull, but the impulse of that force is also transmitted to the ship itself, which moves. The energy that the mooring ship takes 
over is transferred to the mooring ropes, which must limit the movement. The movement of the moored ship is contained as long as the mooring lines are intact; when they break, the ship would float freely, causing additional risk. Particularly critical is the movement during cargo operations. An excessive movement of the ship could cause damage to a loading crane on a bulk carrier or a pipe breaking on a tanker ship or extensive damage to a cargo ramp on a Ro-Ro ship, etc. The model presented on Figure 11 limits the permissible displacement of $4 \mathrm{~m}$ in the longitudinal direction. The model is based on a formulation of the static force equilibrium oriented to the collision point.

$$
\begin{aligned}
& \sum F_{i} x=0 \\
& \sum F_{i} y=0
\end{aligned}
$$
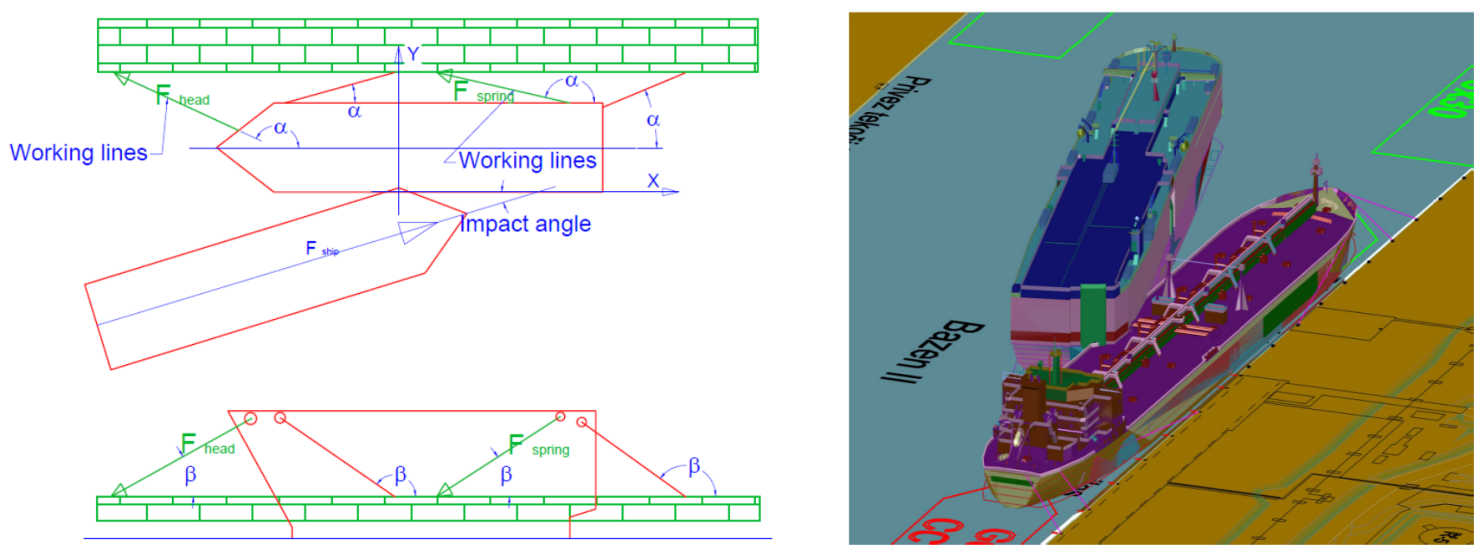

Figure 11. Mooring configuration and rope angles.

The resulting forces in mooring lines are $F_{\text {head }}$ and $F_{\text {spring }}$ (Figure 11), calculated considering the horizontal and vertical position of the lines. According to the mooring configuration and the collision direction, the force of the collision is transferred to the mooring lines but also to the fenders on the banking side of the ship. In fact, part of the moving energy is converted to friction between the ship hull and fenders. The presented mooring model also considers the friction force resulting from the impact force in the $y$ direction and the friction coefficient (0.5).

Table 4 shows the length of engaged mooring lines and their angles according to the ship mooring plan at the port terminal. The number of lines could vary and depends on the weather condition, but for steady conditions, the mooring configuration is as presented. The longitudinal force transferred from the colliding to the struck ship is transferred to the two headlines and two spring lines.

Table 4. Mooring lines positions and length for the lateral collision model.

\begin{tabular}{lccccl}
\hline & Length & Alpha & Beta & No. & \\
\hline Head 1. & 60 & 140 & 20 & 2 & in use \\
Stern 1. & 45 & 150 & 15 & 2 & not in use \\
Breast 1. FW & 55 & 120 & 15 & 2 & not in use \\
Breast 1. ST & 38 & 160 & 15 & 2 & not in use \\
Spring 1. FW & 42 & 170 & 15 & 1 & not in use \\
Spring l. ST & 90 & 170 & 10 & 2 & in use \\
\hline
\end{tabular}

According to the force equilibrium equations, the tension on the engaged ropes is calculated considering the collision speed and angle. Most of the force is transferred to the spring line as its angle is almost in line with that of the pier. Figure 12 shows the calculated forces on headlines and spring lines that take on the impact force. 


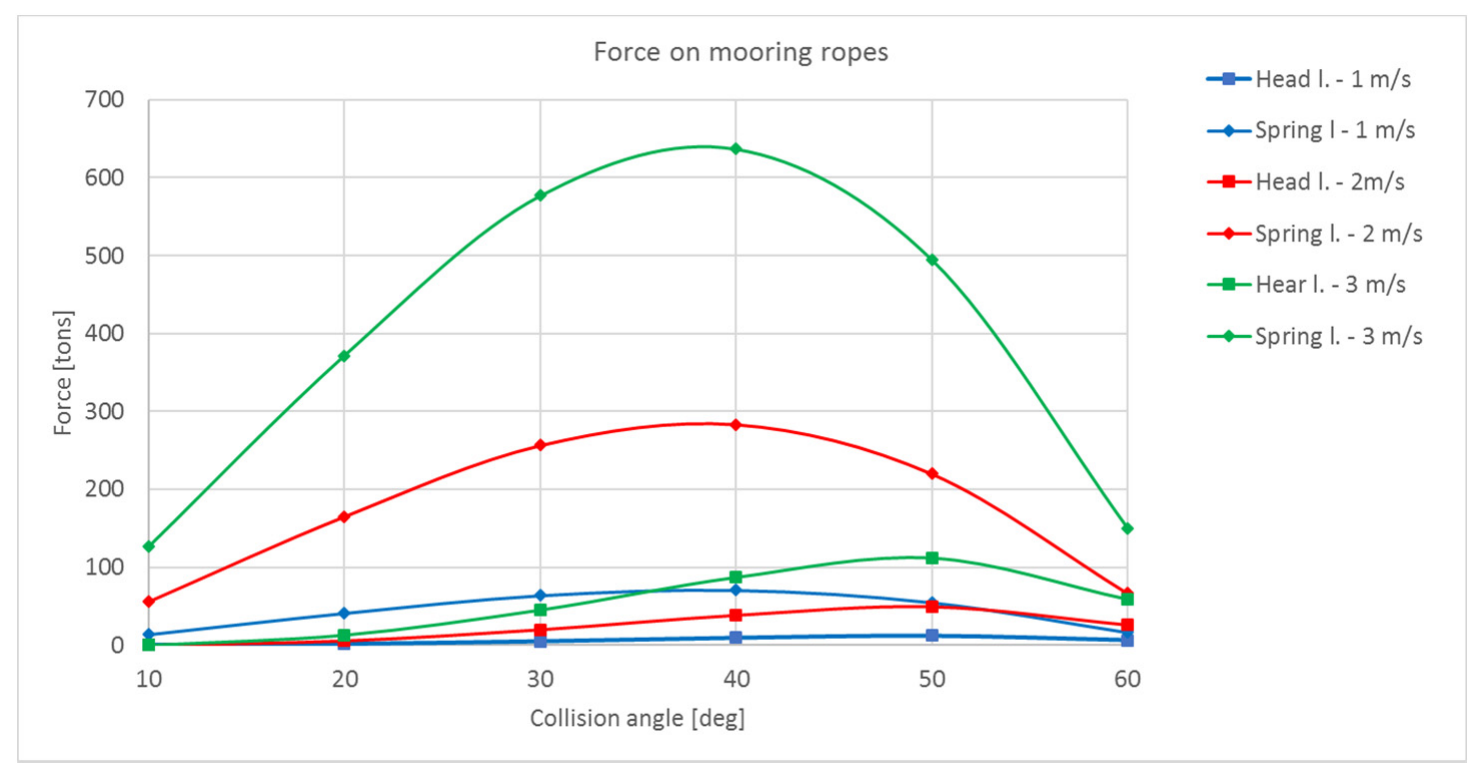

Figure 12. Force on mooring ropes caused by the collision.

Furthermore, the calculation of mooring ropes is performed. According to the equipment number, each ship applies specific mooring equipment, which includes the working load of mooring ropes and their size. As the market offers different types of mooring ropes, made from different materials, the model below assumes two type of ropes. The first is a high tensile aramid rope with a diameter of $50 \mathrm{~mm}$ and a breaking load of 180 tons, the second is polypropylene rope with a diameter of $80 \mathrm{~mm}$ and a breaking load of 105 tons. The maximum allowable elongation of each rope presented in Table 5 is used to calculate the extension of the rope under load condition and to determine when the extension overcomes the maximum allowable ship movement. As observed in the table, the aramid ropes are more likely to break in excessive load condition. The polypropylene ropes work with more elasticity and could not keep the moored ship in position even in low speed collisions or contacts.

Table 5. Calculation of forces in mooring lines, extensions and tear points.

\begin{tabular}{|c|c|c|c|c|c|c|c|}
\hline \multicolumn{4}{|c|}{ Rope Elongation $\mathrm{d}=50 \mathrm{~mm}$, Mooring Line (Aramid) [m]. } & \multicolumn{4}{|c|}{ Rope Elongation $\mathrm{d}=80 \mathrm{~mm}$. Mooring Line (Polypropilene) $[\mathrm{m}]$} \\
\hline Max Load [ton] & & \multicolumn{2}{|c|}{180} & Max Load [ton & & \multicolumn{2}{|c|}{105} \\
\hline Elongation [\%] & & \multicolumn{2}{|c|}{$5 \%$} & Elongation [\% & & \multicolumn{2}{|c|}{$18 \%$} \\
\hline Head 1./Spring 1. ST & & \multicolumn{2}{|c|}{ Aramid line } & Head 1./Spring & & \multicolumn{2}{|c|}{ Polyester line } \\
\hline Head l. $10^{\circ}$ & 60.00 & 60.00 & 60.00 & Head $1.10^{\circ}$ & 60.00 & 60.00 & 60.00 \\
\hline $30^{\circ}$ & $\begin{array}{l}60.04 \\
90.80\end{array}$ & $\begin{array}{l}60.17 \\
93.21\end{array}$ & $\begin{array}{l}60.38 \\
\text { Break }\end{array}$ & $30^{\circ}$ & $\begin{array}{c}60.26 \\
\text { Max } \\
\text { movement }\end{array}$ & $\begin{array}{l}61.04 \\
\text { Break }\end{array}$ & $\begin{array}{l}62.33 \\
\text { Break }\end{array}$ \\
\hline $40^{\circ}$ & $\begin{array}{l}60.08 \\
90.89\end{array}$ & $\begin{array}{l}60.32 \\
93.54\end{array}$ & $\begin{array}{l}60.73 \\
\text { Break }\end{array}$ & $40^{\circ}$ & $\begin{array}{c}60.50 \\
\text { Max } \\
\text { movement }\end{array}$ & $\begin{array}{l}62.00 \\
\text { Break }\end{array}$ & $\begin{array}{c}\text { Max movement } \\
\text { Break }\end{array}$ \\
\hline $60^{\circ}$ & $\begin{array}{l}60.06 \\
90.21\end{array}$ & $\begin{array}{l}60.22 \\
92.83\end{array}$ & $\begin{array}{l}60.49 \\
91.87\end{array}$ & $60^{\circ}$ & $\begin{array}{l}60.34 \\
91.28\end{array}$ & $\begin{array}{c}61.35 \\
\text { Max movement }\end{array}$ & $\begin{array}{c}63.04 \\
\text { Max movement }\end{array}$ \\
\hline
\end{tabular}


The values in Table 5 represent the lengths of ropes under collision load conditions. When the calculated length of the rope exceeds the allowable elongation percent, it is indicated as "Max movement", and when the calculated load on a rope exceeds the breaking load, it is indicated as "Break".

According to the calculated consequences in this analysis, the following risk control options (RCO) are considered as follows:

1. Speed reduction while passing near the berth of a moored ship,

2. Restrictions or prohibiting bunkering or liquid cargo operation during the passage of a large passenger ship,

3. Speed limit or prohibition of passages near a moored chemical ship,

4. Special navigational markings,

5. Mandatory tugboat requirements.

\section{Risk Evaluation}

The risk evaluation applies the event tree for the collision event. The basic structure of the event tree is based on the MEPC report [31] and is used for the calculation of PLP. The assumption of property loss is based on Table 6 and the event tree for a collision is presented in Figure 13. Values in Table 6 are based on a total loss of a new ship, in this case a Panamax size, and divided in bands according to a damage extent. The similar approach was used in the IMO Formal Safety Assessment [23].

Table 6. Ship size characteristics and consequence bands for Panamax ship size.

\begin{tabular}{rc}
\hline \multicolumn{1}{l}{ Panamax } & \% Damage Extent \\
\hline \multicolumn{1}{l}{ Property } & \\
\hline $74,193.00 €$ & $0.00 \%$ \\
$185,484.00 €$ & $0.10 \%$ \\
$370,968.00 €$ & $0.25 \%$ \\
$741,937.00 €$ & $0.50 \%$ \\
$1,854,843.00 €$ & $1.00 \%$ \\
$3,709,687.00 €$ & $2.50 \%$ \\
$11,129,062.00 €$ & $5.00 \%$ \\
$18,548,437.00 €$ & $1.00 \%$ \\
$22,258,125.00 €$ & $2.00 \%$ \\
$37,096,875.00 €$ & $30.00 \%$ \\
$51,935,625.00 €$ & $50.00 \%$ \\
$74,193,750.00 €$ & $70.00 \%$ \\
& $100.00 \%$ \\
\hline
\end{tabular}

The main branches of the collision event tree have four main levels. At the first, the ship is considered as moored or sailing (stuck or striking), the second is the area of the accident (terminal area, congested waters, open waters, or limited waters), the third is the loading condition (loaded or in ballast), and next is the accident magnitude where the hull could be breached or not. Double hull penetration or single hull ship type are also considered. The probability of each branch is partially obtained from the MEPC report but modified with the statistical data from the Port of Koper and the police port. The initial collision probabilities for two ports have been previously calculated in paragraph 3 and used in the event tree. The final probabilities of each branch and the risk are calculated and further used for the design of the risk curve. The collision risk is here presented with the F-N curve for a panamax ship. The PLP risk for larger ships could exceed the tolerable risk mainly because of the higher ship value, which is why the average ship size is considered. 


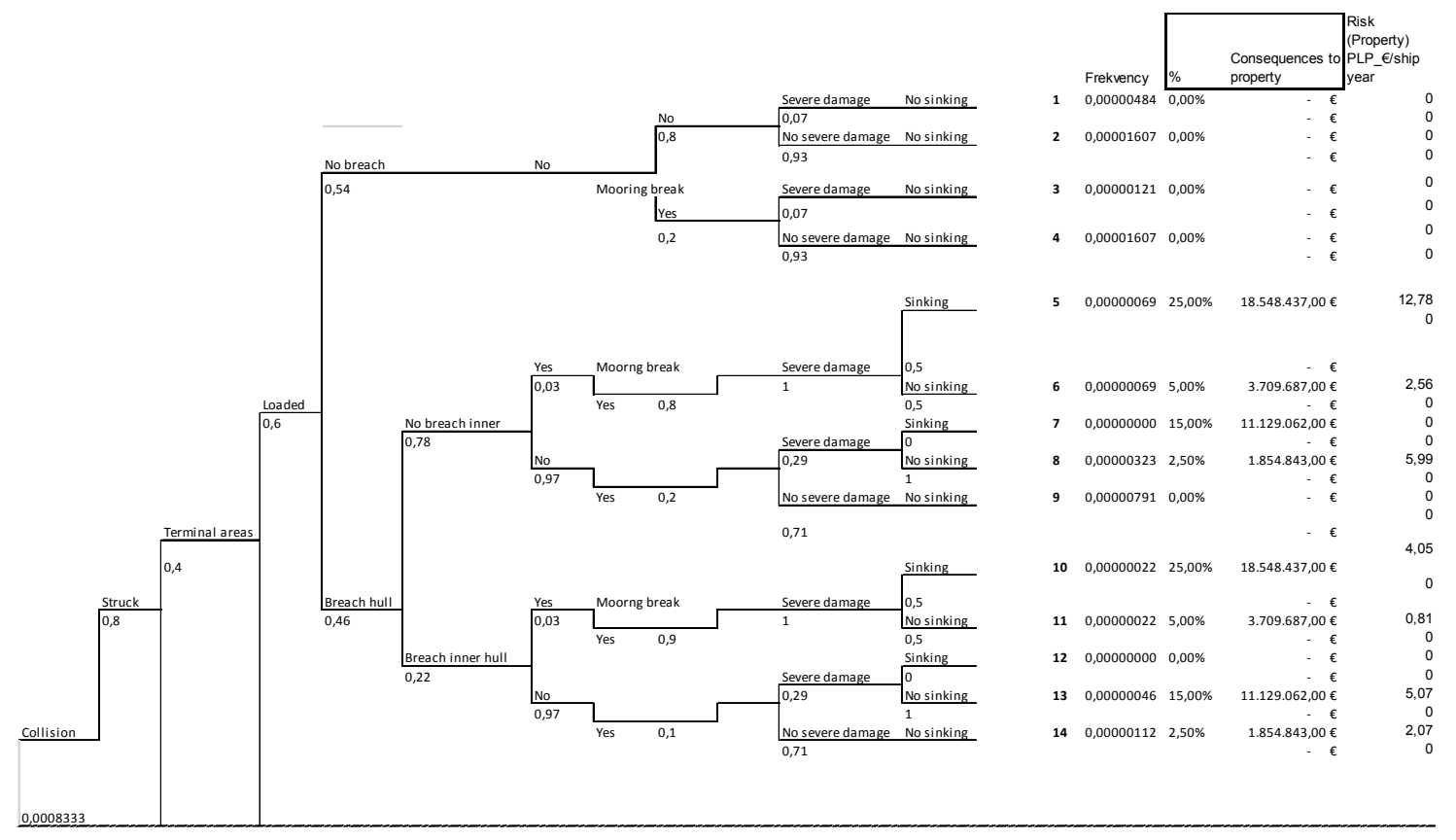

Figure 13. Ship collision event tree (part).

Figure 14 shows the economic aspect of the risk where the PLP graph above shows that the property losses, due to collision accidents, do not produce relevant economic risk to the port. It should be noted that risks should be considered together, especially those which are directly related with the cost benefit. The second is the risk curve for the police port that is lower than the Port of Koper only because the initial probability is lower than that calculated for the Port of Koper. Considering that the probability of mooring failure during the collision in port influences the risk curve in the range of 0.1 to 10 M EUR damage, the findings mean that the mooring break of a ship should be considered in the risk assessment, although in the analysed port the risk in both cases is within the acceptable area. The presented results quantitatively suggest the importance of a proper mooring arrangement assuming the probability of a collision in a terminal area.

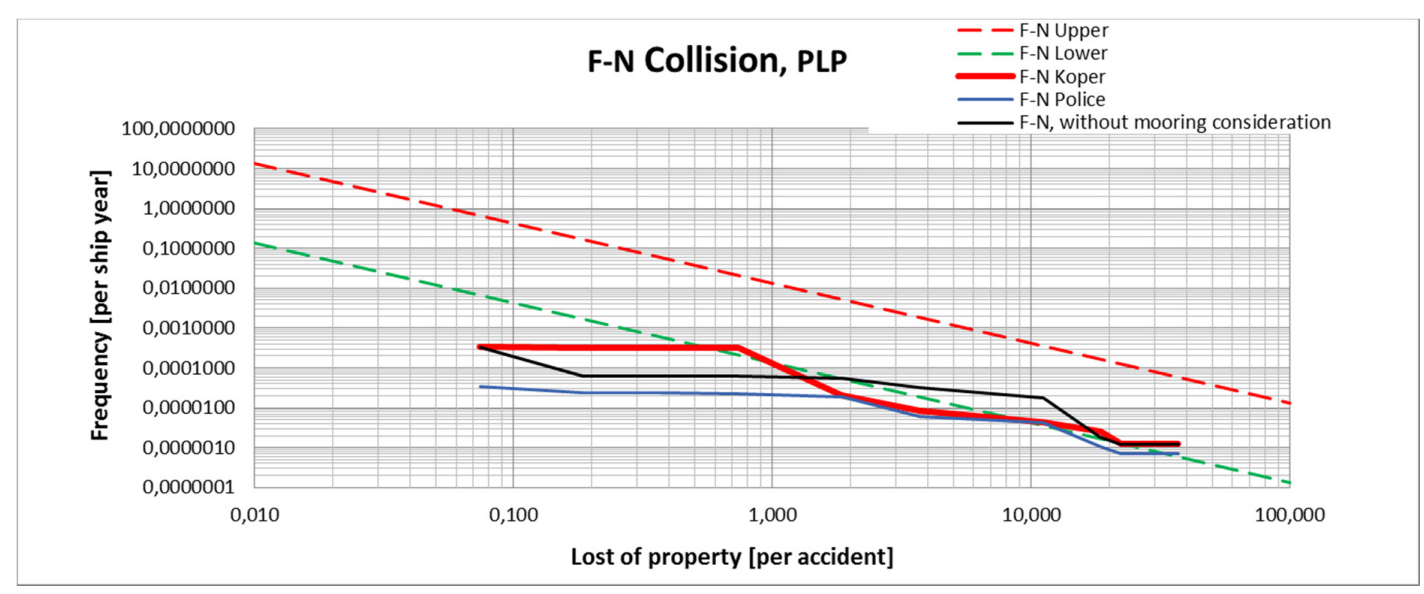

Figure 14. Collective risk level for an average ship size in port for collision event.

Considering the findings from Section 5 , the approaching speed to a terminal basin should be about 2 to 3 knots and the approaching angle towards a moored ship not more than $30^{\circ}$. Exceeding these values, the moored ship would break the mooring ropes and move from its mooring position. The F-N curve where the mooring failure is not considered shows that the accident with the same probability 
of collision could result in property loss that is $8 \mathrm{M}$ EUR higher than when the mooring failure is considered.

\section{Conclusions}

The problem of the coexistence of dangerous cargo terminals with ship traffic requires assured acceptable risk levels in port areas. The aim of the presented method is to provide decision makers with a methodological framework for calculating the risk along with practical actions that should be taken to minimize this risk to an acceptable level. Such actions could be implemented as port regulations.

The method and framework presented in the paper is aimed at determining the risk of a possible collision between a passing ship and a moored ship. It should be noted that the simulation method was used to determine the maximum physically possible speed and angle of contact in a potentially catastrophic scenario accident. Usually, in restricted port areas, there is no possibility of achieving such high energies and angles of impact; in such a case, there is no need to carry out such extensive investigations. The consequences model was applied by changing input parameters. The maximum acceptable speed of a passing ship is calculated based on the consequences to the moored ship and its break from the moored position. According to the calculated probability of collision and consequences, the risk is evaluated. The event tree approach is applied where the risk is presented with the F-N curve. The event tree is found to be the most appropriate approach as the methodology framework, as it can be constantly upgraded with new events and the probabilities of branch events may be modified on a monthly or yearly basis according to port statistics. The paper demonstrates that considering the mooring characteristics in a risk assessment of the port could reduce the risk through acknowledging that a collision accident would not result in extremely high consequences for ships and structures. The cost of a stronger mooring arrangement is minimal, while the savings could be considered in the millions for a single accident.

This paper demonstrates that previously developed frameworks for maritime risk analysis did not fully cover the accident type presented here (collision). The presented work and framework can be used for port policy making. As the engineering conclusion from the case study, which was used as an example, the large ships reducing speed is the most economical solution along with navigating with caution when a sensitive ship is moored in the passageway of the approaching ship.

Author Contributions: Conceptualization, L.G. and P.V.; methodology, P.V.; investigation, K.Ł.; resources, M.P.; data curation, K.Ł.; writing—original draft preparation, L.G.; writing—review and editing, P.V. All authors have read and agree to the published version of the manuscript.

Funding: The publication of the paper is partially financed by the research project and the research group at the Faculty of Maritime Studies and Transport, financed by the Slovenian National Research Agency.

Conflicts of Interest: The authors declare no conflict of interest.

\section{References}

1. Port Marine Safety Code; 2012. Available online: https://assets.publishing.service.gov.uk/government/uploads/ system/uploads/attachment_data/file/918935/port-marine-safety-code.pdf (accessed on 31 August 2020).

2. Billington, C.J. Managing Risks in Shipping: A Practical Guide; The Nautical Institute: London, UK, 2001.

3. ISPS. International Ship and Port Facility Security Code; International Maritime Organization: London, UK, 2003.

4. Ayman, N.; Wolfgang, K. Risk Assessment Methods in Seaports: A Literature Review. In HAZARD Project; University of Turku: Turku, Finland, 2018.

5. Chlomoudis, C.I.; Kostagiolas, P.; Pallisa, P.L. An Analysis of Formal Risk Assessments for Safety and Security in Ports: Empirical Evidence from Container Terminals in Greece. J. Shipp. Ocean. Eng. 2012, 2, 45-54.

6. Kontovas, C.A.; Psaraftis, H.N. Formal Safety Assessment: A Critical Review. Mar. Technol. 2009, 46, 45-59.

7. Pallis, P.L. Port Risk Management in Container Terminals. World Conference on Transport Research. Transp. Res. Procedia 2016, 25, 4411-4421. [CrossRef] 
8. Gucma, L. Maritime Risk Management; Maritime University of Szczecin: Szczecin, Poland, 2009.

9. Trbojevic, V.; Carr, B. Risk based methodology for safety improvement in ports. J. Hazard. Mater. 2000, 71, 467-480. [CrossRef]

10. Aven, T. Risk Analysis: Assessing Uncertainties beyond Expected Values and Probabilities; John Wiley \& Sons Ltd.: Hoboken, NJ, USA, 2008.

11. Kristiansen, S. Maritime Transportation: Safety Management and Risk Analysis; Elsevier Butterworth-Heinemann: Amsterdam, NY, USA, 2005.

12. Van, W.H.; Pinkster, J. The Effects of Ships passing Moored Container Vessels in the Yangtzehaven, Port of Rotterdam. In Proceedings SOCW 2008 Conference; Varyani, K.S., Ed.; University of Strathclyde: Glasgow, UK, 2008.

13. Pearson, J.; Kuzmin, V.; Clouter, E. Application of FSA in Polar Transportation; IAMU Published Research Project; IAMU: Ankeny, IA, USA, 2015.

14. Wang, J.; Foinikis, P. Formal Safety Assessment for Containership. Marit. Policy 2001, 25, 143-157. [CrossRef]

15. Zec, D.; Zorović, D.; Vranić, D. Impact of the Formal Safety Assessment on Shipboard Operations. Sci. J. Traffic Transp. Res. 1998, 10, 127-130.

16. Goerlandt, F.; Montewka, J. Maritime transportation risk analysis: Review and analysis in light of some foundational issues. Reliab. Eng. Syst. Saf. 2015, 138, 115-134. [CrossRef]

17. Dong, Y.; Frangopol, D. Probabilistic ship collision risk and sustainability assessment considering risk attitude. Struct. Saf. 2014, 53, 75-84. [CrossRef]

18. Rokseth, B.; Utne, I.B.; Vinnem, J.E. A systems approach to risk analysis of maritime operations. J. Risk Reliab. 2016, 231, 53-68. [CrossRef]

19. Dhami, H.; Grabowski, M. Technology impacts on safety and decision making over time in marine transportation. Proc. Inst. Mech. Eng. J. Risk Reliab. 2011. [CrossRef]

20. Vanem, E.; Puisa, R.; Skjong, R. Standardized Risk Models for Formal Safety Assessment of Maritime Transportation. In Proceedings of the 28th International Conference on Ocean, Offshore and Arctic Engineering, Honolulu, HI, USA, 31 May-5 June 2009.

21. Stewart, M.G. Acceptable Risk Criteria for Infrastructure Protection. Int. J. Prot. Struct. 2010, 1, $23-40$. [CrossRef]

22. Vidmar, P.; Perkovič, M. Methodological approach for safety assessment of cruise ship in port. Saf. Sci. 2015, 80, 189-200. [CrossRef]

23. MEPC. MAPC 8/INF.2, Formal Safety Assessment-Crude Oil Tankers; International Maritime Organization: London, UK, 2008.

24. Artyszuk, J. Towards a Scaled Manoeuvring Mathematical Model for a Ship of Arbitrary Size. Sci. J. Marit. Univ. Szczec. 2005, 6, 21-37.

25. La Scola, E.; Mermiris, G. Towards an integrated approach to collision and grounding damage assessment. In Collision and Grounding of Ships and Offshore Structures; Taylor \& Francis Group: Abingdon, UK, 2013.

26. Ehlers, S.; Tabri, K. A combined numerical and semi-analytical collision damage assessment procedure. Mar. Struct. 2012, 28, 101-119. [CrossRef]

27. Tabri, K. Dynamics of Ships Collisions. Ph.D. Thesis, Aalto University, Espoo, Finland, 2010.

28. Sormunen, O.; Ehlers, S.; Kujala, P. Collision consequence estimation model for chemical tankers. In Proceedings of the Institution of Mechanical Engineers. J. Eng. Marit. Environ. 2012, 227, 98-106.

29. Zhang, S. The Mechanics of Ship Collisions. Ph.D. Thesis, Technical University of Denmark: Kongens Lyngby, Denmark, 1999.

30. Pedersen, P.; Zhang, S. The Mechanics of ships impact against the bridges. In Proceedings of the International Symposium on Advances in Ship Collision Analysis, Copenhagen, Denmark, 10-13 May 1998. 
31. Reardon, P.; Sprung, J. Validation of Minorsky's Ship Collision Model and Use of the Model to Estimate the Probability of Damaging a Radioactive Material Transportation Cask During a Ship Collision. In Proceedings of the International Conference on Design and Methodologies for Collision and Grounding Protection of Ships, San Francisco, CA, USA, 22-23 August 1996.

32. Paté-Cornell, M.E. Uncertainty in Risk Analysis: Six Levels of Treatment. Reliab. Eng. Syst. Saf. 1996, 54, 95-111. [CrossRef]

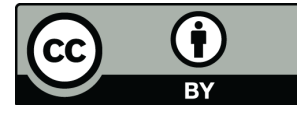

(C) 2020 by the authors. Licensee MDPI, Basel, Switzerland. This article is an open access article distributed under the terms and conditions of the Creative Commons Attribution (CC BY) license (http://creativecommons.org/licenses/by/4.0/). 